\title{
Carbimazole Drug-Induced Hepatitis during Treatment of Graves' Disease: About Four Cases at Dakar Teaching Hospital
}

\author{
Abdoulaye Leye*, Michel Assane Ndour, Nafy Ndiaye Sarr, Ngoné Diaba Diack, \\ Yakham Mohamed Leye, Dominique Emmanuel Faye
}

Internal Medicine and Endocrinology Department, Teaching Hospital of Pikine, Dakar, Senegal

Email: *abl ayleye@hotmail.com

How to cite this paper: Leye, A., Ndour, M.A., Ndiaye, N., Diack, N.D., Leye, Y.M. and Faye, D.E. (2017) Carbimazole Drug-Induced Hepatitis during Treatment of Graves' Disease: About Four Cases at Dakar Teaching Hospital. Open Journal of Internal Medicine, 7, 97-104.

https://doi.org/10.4236/ojim.2017.74010

Received: September 17, 2017

Accepted: October 15, 2017

Published: October 18, 2017

Copyright $\odot 2017$ by authors and Scientific Research Publishing Inc. This work is licensed under the Creative Commons Attribution International License (CC BY 4.0).

http://creativecommons.org/licenses/by/4.0/

\begin{abstract}
Introduction: Mostly reported common side effects of carbimazole are cutaneous allergies and severe agranulocytosis. However, hepatotoxicity is rarely described. Thus, we report four observations of carbimazole drug-induced hepatitis during the treatment of Graves' disease, which imputability is likely and probably an immuno-allergic mechanism. Observations: They were four women whose average age was 43 years, with extreme ages of 32 and $54 . \mathrm{Pa}-$ tients were monitored and treated with carbimazole in doses contained between $40 \mathrm{mg}$ and $60 \mathrm{mg}$ per day. Clinical manifestations of liver injury were mainly dominated by cholestatic jaundice, found in $100 \%$ of our patients. A painful sensitivity of the right hypochondrium was concomitant with jaundice for two patients. The jaundice time to onset after the beginning of treatment with carbimazole varies between 1 month and 6 months. They all had acute hepatitis. The biological assays used to determine the type of liver injury showed, in all cases, a mixed, cholestatic and cytolytic hepatitis. Therapeutically, in all patients, carbimazole was stopped as soon as the suspicion of its incrimination in the occurrence of liver damage was set up. They all had a substitution of carbimazole with benzylthiouracil. Evolution was favorable for all patients, after therapeutic substitution. It was marked by disappearance of jaundice and normalization of the liver biological parameters within a maximum delay of two months after stopping carbimazole use. Conclusion: Treatment with synthetic antithyroid drugs, particularly carbimazole that is most widely used in our regions, requires clinical and biological monitoring. This surveillance, which is often difficult in Africa because of the limited economic resources, can lead to the occurrence of side effects such as potentially serious drug-induced hepatitis, but which has been favorable in our observations.
\end{abstract}




\section{Keywords}

Drug-Induced Hepatitis, Carbimazole, Graves’ Disease

\section{Introduction}

Hyperthyroidisms refer to an unstoppable overproduction of thyroid hormones, by all or just a part of the thyroid gland. The etiologies are numerous but remain dominated by Graves' disease. It is liable for about $80 \%$ - 90\% hyperthyroidism cases in India [1], 70\% of hyperthyroidism in France [2], and $82 \%$ of cases in Cameroon [3]. In Senegal, it represents $72 \%$ of the patients treated for hyperthyroidism [4]. Graves' disease is the most common specific organ auto-immune disease [5]. Its diagnosis is usually set up when occur clinical and biological symptoms of hyperthyroidism with homogeneous goiter and mostly an ophthalmopathy.

The treatment of this auto-immune disease rests on three alternative methods: medicinal, surgical, and isotopic. The medical treatment is the therapeutic method always advised in first line treatment. It uses synthetic anti-thyroid drugs, and carbimazole is the molecule chosen in the therapeutic range [6]. But like any medicinal product, it can cause significant side effects. Some are well known, such as skin rash, arthralgia, or even agranulocytosis, which is the most feared. Others are less well known. This is the case of induced hepatotoxicity. This is a rare but not insignificant side effect of antithyroid treatment [7]. Only a few cases have been described in the literature. In Senegal, no case has been reported so far. Our purpose is to analyze the diagnostic and therapeutic difficulties encountered in drug-induced hepatitis with carbimazole during the treatment of Graves' Disease, through four observations collected between March 2010 and May 2016 that we report.

\section{Observations}

\subsection{Observation 1}

A 54-year-old hypertensive woman on ramipril $10 \mathrm{mg}$ per day for 4 years was hospitalized in the internal medicine department for a thyrotoxicosis syndrome running for 2 months. We noticed effort dyspnea, palpitations, heart erethism, excessive sudation and nervosity, transit acceleration, associated with psychomotor agitation, loss of weight unrecorded. Physical examination showed a regular tachycardia, a painless homogeneous goiter, elastic and painless, a discreet bilateral exophthalmia reducible. There was no jaundice.

At the paraclinic, the TSH level was lower than $0.001 \mathrm{IU} / \mathrm{L}(\mathrm{N}: 0.4-4.3)$ and the T4 level totaled $32.30 \mathrm{pmol} / \mathrm{l}(\mathrm{N}: 9$ - 12). Transaminases were normal with ASAT at $29 \mathrm{IU} / \mathrm{l}(\mathrm{N}: 5-34)$ and ALAT at $24 \mathrm{U} / \mathrm{l}(\mathrm{N}: 0$ - 55) as well as bilirubin. Fasting blood glucose was normal. Thyroid ultrasound showed a heterogeneous 
hyper-vascular goiter (Figure 1). The scintigraphy had not been done. The diagnosis of Grave's disease was set up.

She was on carbimazole medication at a dose level of $60 \mathrm{mg}$ taken 3 times per day, combined with propranolol $40 \mathrm{mg} / \mathrm{d}$ in 2 doses. Forty-five days later, the signs of thyrotoxicosis had diminished and the dose of carbimazole was reduced to $40 \mathrm{mg}$ per day. However, she presented a cholestatic jaundice without fever. The examination showed a sensitivity of the right hypochondrium without any hepatomegaly. The patient did not report treatment by herbal medicine or other drugs, particularly hepatotoxic drugs. In the biology, it was noticed at the blood count, a level of eosinophils at $0.53 \mathrm{G} / \mathrm{l}$; a cholestasis syndrome with an increase of bilirubin rate equal to $75 \mathrm{mg} / \mathrm{l}$ with a $57.3 \mathrm{mg} / \mathrm{l}$ conjugated bilirubin predominance, $670 \mathrm{IU} / \mathrm{l}$ of alkaline phosphatase at 4.5 times normal, gamma glutamyl transferase at $395 \mathrm{IU} / \mathrm{L}$ was 6 fold higher. Hepatic cytolysis with ASAT at 121 IU/l was 2.4 times normal and ALAT at 132 was 3.55 times normal. The search for the HBs antigen was negative as well as the search for antibodies against the following viruses: HCV, HAV, HEV, CMV, EBV, Herpes. The free T4 control level was lowered to $21.75 \mathrm{pmol} / \mathrm{l}$. Abdominal ultrasound was normal. The electrocardiogram was normal, cardiac ultrasound showed dilatation of the left atrium. These elements led to the conclusion that acute drug hepatitis was probably associated with Carbimazole which prompted the drug to be stopped and substituted with benzylthiouracil.

The evolution was marked 2 months later by the regression of the clinical signs in particular the jaundice, the normalization of the transaminases with ASAT at $28 \mathrm{IU} / \mathrm{L}$ and the ALAT at $22 \mathrm{IU} / \mathrm{l}$ and the biological cholestasis syndrome (Table $1)$.

\subsection{Observation 2}

Mrs. A. K. was 37 years old, with no previous medical history, divorced and mother of a child. She was followed for hyperthyroidism for 6 months before. The examination found a syndrome of thyrotoxicosis, a vascular goiter with discrete bilateral exophthalmia. The TSHus level was less than 0.005 IU/L. There

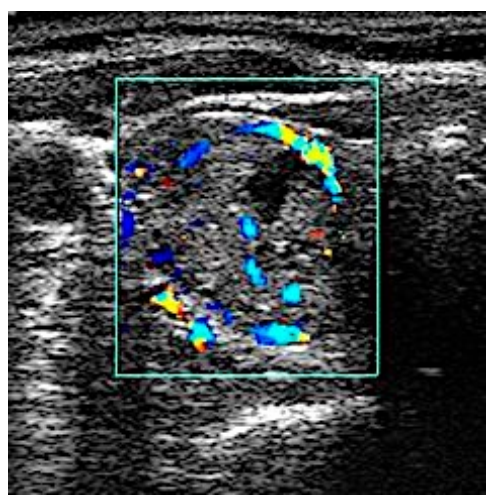

Figure 1. Ultrasound features showing heterogeneous hyper-vascular goiter. 
Table 1. Evolution of hepatic function under carbimazole.

\begin{tabular}{|c|c|c|c|c|c|c|}
\hline $\begin{array}{c}\text { Carbimazole } \\
\text { (mg/day) }\end{array}$ & $\begin{array}{c}\text { ASAT } \\
(\mathrm{UI} / \mathrm{L}) \\
(\mathrm{N}: 5-34)\end{array}$ & $\begin{array}{c}\text { ALAT } \\
(\mathrm{UI} / \mathrm{L}) \\
(\mathrm{N}: 0-55)\end{array}$ & $\begin{array}{c}\text { Phosphatases } \\
\text { Alkalines } \\
\text { (UI/L) } \\
(\mathrm{N}: 40-150)\end{array}$ & $\begin{array}{c}\text { GGT UI/L } \\
(\mathrm{N}: 12-64)\end{array}$ & $\begin{array}{c}\text { Total } \\
\text { Bilirubin } \\
(\mathrm{mmol} / \mathrm{L}) \\
(\mathrm{N}: 2-12)\end{array}$ & $\begin{array}{c}\text { Direct Reacting } \\
\text { Bilirubin } \\
(\mathrm{mmol} / \mathrm{L}) \\
(\mathrm{N}: 0-5)\end{array}$ \\
\hline Before & 29 & 24 & 119 & 23 & 5 & 2 \\
\hline 60 & 121 & 132 & 670 & 395 & 7.5 & 57.3 \\
\hline 40 & 100 & 130 & 250 & 250 & 38 & 26 \\
\hline After & 28 & 22 & 140 & 70 & 10 & 3 \\
\hline
\end{tabular}

ASAT: aspartate amino transferase; ALAT: alanine amino transferase; GGT: gamma-glutamyl transferase.

was no jaundice. She was on carbimazole since then at a daily dose of $40 \mathrm{mg}$. Her follow-up was irregular. After 6 months of treatment, she presented a non-febrile jaundice. Among the complaints there were palpitations and pain in the right side. There was neither notion of herbal medicine in the interrogation, nor of taking other drugs, especially hepatotoxic. The physical examination showed no hepatomegaly. In biology, there was an isolated elevation of ASAT to $134 \mathrm{IU} / \mathrm{L}$, and ALAT to $25 \mathrm{IU} / \mathrm{L}$. The second dose of liver enzymes showed a more important increase of transaminases a month later: ASAT $265 \mathrm{IU} / \mathrm{L}$ and ALAT 142 IU/L. However, the search for HBs antigen, HCV antibodies, HAV, VHE, CMV, EBV, HERPES serology could not be performed, because of lack of means, as well as abdominal ultrasound. Acute hepatitis was deduced. In view of the suspicion of the incrimination of carbimazole, and in the absence of another obvious cause, a new treatment was given with benzylthiouracil at a dose level of $100 \mathrm{mg}$ two times a day in order to replace carbimazole, and a betablocker with an anxiolytic. The evolution after the stopping of carbimazole was marked by the regression of the symptoms, in particular the disappearance of jaundice in two months, and by a significant secondary decrease of the transaminase level, with ASAT at $39 \mathrm{IU} / \mathrm{L}$ and ALAT at $84 \mathrm{IU} / \mathrm{L}$. The patient had evolved well under benzylthiouracil, with a disappearance of signs of thyrotoxicosis, a decrease of goiter, a progressive decrease in the free T4 level, a stable normalization of the liver transaminase level and a constant and progressive weight gain of $17 \mathrm{Kg}$ within two years.

\subsection{Observation 3}

Ms S.E.A, aged 49 years, was hospitalized for hyperthyroidism complicated with cardiothyreosis, associated with acute hepatitis. She was monitored in Mauritania, and treated with carbimazole. However, the beginning of the treatment and the daily dose of carbimazole could not be specified. There was no notion of herbal medicine during the interrogation, nor of taking other drugs, notably hepatotoxic.

When being admitted, the physical examination found a vascular goiter, associated with acquired exophthalmia, and mucocutaneous jaundice. The thyroid ultrasound showed a regular hypervascularized goiter, with a hypo-echogenic in- 
fra-centimeter nodule on the right lower lobe.

Biological examinations showed a cholestasis syndrome with a total bilirubin rate at $186 \mathrm{mg} / \mathrm{L}$, predominantly conjugated $(171 \mathrm{mg} / \mathrm{L})$ and liver cytolysis, with ALAT at $145 \mathrm{IU} / \mathrm{L}$ and ASAT at $138 \mathrm{IU} / \mathrm{L}$. The search for circulating antibodies (anti-platelet, anti-nuclear, anti-cardiolipin IgG and IgM antibodies) returned negative; viral serology had not been possible. Abdominal MRI did not show any obstructions on the biliary tract or any other specific abnormality. Drug-induced hepatitis with carbimazole was therefore suspected and the drug was stopped at the start of hospitalization. She was given betablocker, antihypertensive, anticoagulant in order to control the symptoms of cardiothyreosis, and she was on benzylthiouracil medication at a dose level of $225 \mathrm{mg}$ tree times per day, to replace carbimazole.

The evolution was favorable after stopping the carbimazole. A complete regression of jaundice, and a normalization of bilirubinemia, was noted in particular after two months.

\subsection{Observation 4}

A 32-year-old patient with no previous specific medical history was referred for physical asthenia and an unnumbered weight loss. The interrogation found a chronic anxiety, irritability and insomnia. There was an acceleration of transit after food ingestion, palpitation, especially nocturnal and hypersudation. The physical examination found an anterior cervical mass of vascular appearance, a myogenic syndrome in the pelvic girdle with a sign of the positive stool, and a moistening of the hands. There was no exophthalmia or jaundice. Biological examinations showed: a TSHus level lower than $0.005 \mathrm{IU} / \mathrm{L}$, a free T4 level at $50 \mathrm{ng} / \mathrm{L}$. The dosage anti-receptor to TSH antibody was positive. Transaminases were normal with ASAT at $14 \mathrm{IU} / \mathrm{L}$ and ALAT at $20 \mathrm{IU} / \mathrm{L}$.

The patient was treated with carbimazole at a dose of $45 \mathrm{mg}$ per day in 3 doses, propanolol $80 \mathrm{mg}$ in 2 doses, and on anxiolytic medication. After one month of treatment, the patient returned to the consultation for intense pruritus associated with dark sparkling urine. No notion of herbal medication was noted during the interrogation. The physical examination revealed a frank cutaneous mucous discharge of cholestatic appearance. The biological tests performed showed hepatic cytolysis with ASAT at $768 \mathrm{IU} / \mathrm{L}, \mathrm{ALAT}$ at $650 \mathrm{IU} / \mathrm{L}$ and a biological cholestasis syndrome. The carbimazole was stopped, and replaced with benzylthiouracil at a dose of $150 \mathrm{mg} /$ day.

The evolution was favorable with progressive regression of cholestatic jaundice and normalization of the liver biological constants in 6 weeks. After 6 months of treatment with benzylthiouracil, the control of thyroid hormones dosage was normal. There was no side effect noticed so far.

\section{Discussion}

Hepatotoxicity is a known side effect of carbimazole, due to cases reported in the scientific literature. However, it is rare. The frequency of occurrence was esti- 
mated between 0.1 and $0.2 \%$ [7]. Akmal and col. [8] regained a frequency of less than $0.5 \%$. Doho Hiro [9] found 2 cases of cholestatic jaundice in 106 patients treated with carbimazole, a frequency of $1.88 \%$. Wang et al. [10] reported an incidence of 3.17/1000 persons per year, based on a cohort of 46,438 patients on methimazole/carbimazole medication. This rarity has been confirmed in our study and it is showed in the reduced number of cases collected. Over a period of nearly 6 years, only 4 cases of hepatic involvement related to carbimazole were recorded. Patients' age varied from 32 to 54 years. The average age of our patients was 43 years, with extreme ages of 32 and 54 years. This result is consistent with those of Akmal et al. [8], which reported an age of onset of hepatotoxicity beyond 40 years. This adulthood is due to the occurrence of Graves' disease. The feminine predominance was clear, since all four of our cases were feminine. $\mathrm{Pa}$ tients were monitored and treated with carbimazole at doses ranging from 40 to $60 \mathrm{mg}$ per day.

The delay in the appearance of jaundice in our patients, after the beginning of treatment with carbimazole, varies between 1 month and 6 months. According to Woeber K.A. [11], the mean time to onset of hepatic cholestasis is 36 days. Karalus $\mathrm{M}$ and col. [12] reported a case of hepatitis with carbimazole with a delay of one month. Akmal and col [8] found a delay in the onset of carbimazole-induced liver disease, which ranged from a few days to five months. However, Burgin S. [13] reported a case with a delay of 18 months after initial carbimazole administration.

Clinical manifestations of hepatic involvement were mainly dominated by jaundice. It was jaundice of the cholestatic type, not febrile. A painful sensitivity of the right hypochondrium was concomitant with jaundice in two of our patients. This jaundice was found in most of the cases reported in the literature [13] [14]. However, it can sometimes fail. The clinical picture of hepatotoxicity of carbimazole usually includes signs such as jaundice, pruritus, feeling of faintness and asthenia [8].

All of our patients had acute hepatitis. Biological assays have made it possible to specify the mixed character of this hepatitis, cholestatic and cytolytic, as reported by other authors [8] [11], all paraclinical examinations for differential diagnosis, most of which were very costly, especially viral serology, had not been possible for all patients because of our unfavorable socio-economic context. This fact constitutes a brake on the establishment of unfailing diagnosis of drug-induced hepatitis which remains a diagnosis of elimination. Viral hepatitis had been formally eliminated in some cases. Liver biopsy is not necessary in most cases [1].

Accountability criteria play an important role in the diagnosis. The first criterion is the interval between the beginning of the suspected treatment and the liver damage. It is considered suggestive when it is between one week and three months [12]. Clinical signs related to acute hepatitis had begun one month after carbimazole therapy. The second criterion is the disappearance of liver abnormalities after discontinuation of treatment. This criterion was very suggestive when the clinical signs disappeared within a few days and the transaminases de- 
creased by more than $50 \%$ within one week.

The third criterion is the relapse of hepatic abnormalities after accidental re-administration of the causal drug [12]. Re-administration of carbimazole was not considered in our patients. Even if it is an excellent criterion, the risk of fulminant hepatitis is high especially if the mechanism is probably immuno-allergic as in our patients.

From a therapeutic point of view, for all patients, carbimazole was stopped as soon as it was suspected of involvement in liver damage. They all had had substitution of carbimazole with benzylthiouracil. Both families of synthetic antithyroid drugs are known to cause different forms of hepatic lesions. Where carbimazole is responsible for cholestatic lesions, propylthiouracil is responsible for hepatocellular necrosis [7] [15]. But the mechanism of hepatotoxicity is different according to the two families of antithyroid drugs; the replacement of the offending molecule can be carried out with caution with an antithyroid of another family [7].

The evolution was favorable for all our patients, after the therapeutic substitution. It was marked by a disappearance of jaundice and normalization of the liver biological parameters during the two months following the stopping of carbimazole.

\section{Conclusions}

In drug-induced hepatitis with carbimazole, the reversibility of symptoms, characterised by slow and complete remission, is the rule after discontinuation of treatment.

The carbimazole diagnosis of imputability in the occurrence of acute liver disease was therefore retrospectively considered in the light of all chronological, clinical, biological, therapeutic and evolutionary arguments.

\section{Conflict of Interest}

No conflict of interest.

\section{Informed Consent}

Informed consents have been obtained from the patients for reporting the cases.

\section{References}

[1] Kota, S.K., Meher, L.K., Kota, S.K., Jammula, S. and Modi, K.D. (2013) Carbimazole-Induced Cholestatic Hepatitis in Graves' Disease. Indian Journal of Endocrinology and Metabolism, 17, 326-328. https://doi.org/10.4103/2230-8210.109660

[2] Goichot, B. and Caron, P. (2012) Diagnostic and Therapeutic Management of Hyperthyroidism in France Today: Results of the Thyroid Survey. Annals of Endocrinology, 73, 273-275.

[3] Nouedoui, C., Moukouri, E. and Juimo, A.G. (1999) Hyperthyroidism in Yaoundé, Cameroon: Some Epidemiological, Etiological and Therapeutic Aspects: Assessment of Our Experience. Medicine of Black Africa, 46, Article ID: 192198. 
[4] Diagne, N., Faye, A., Ndao, A.C., Djiba, B., Kane, B.S., Ndongo, S. and Pouye, A. (2016) Epidemiological, Clinical, Therapeutic and Evolutionary Aspects of Graves' Disease in Internal Medicine at the CHU Le Dantec Dakar (Senegal). Pan African Medical Journal, 25, 6.

[5] Orgiazzi, J. (2011) Treatment of Baseline Disease: Current Issues. La Presse Médicale, 40, 1155-1162. https://doi.org/10.1016/j.lpm.2011.09.012

[6] Phillipe, J.M. (2009) Graves' Disease. Rev Med Suisse, 5, 764-768.

[7] Cooper, D.S. (2005) Antithyroid Drugs. New England Journal of Medicine, 352, 905-917. https://doi.org/10.1056/NEJMra042972

[8] Akmal, A. and Kung, J. (2014) Propylthiouracil, and Methimazol, and Carbimazole Related Hepatotoxicity. Expert Opinion on Drug Safety, 13, 1397-1406. https://doi.org/10.1517/14740338.2014.953796

[9] Doho Hiro, B.G. (2005) Carbimazole in the Treatment of Baseline Disease in Côte d'Ivoire. Study of Biological Effectiveness and Collateral Effects. MED Thesis, University of Bamako, Bamako, $118 \mathrm{p}$.

[10] Wang, M.T., Lee, W.J., Huang, T.Y., Chu, C.L. and Hsieh, C.H. (2014) Antithyroid Drug-Related Hepatotoxicity in Hyperthyroidism Patients: A Population-Based Cohort Study. British Journal of Clinical Pharmacology, 78, 619-629. https://doi.org/10.1111/bcp.12336

[11] Woeber, K.A. (2002) Methimazole-Induced Hepatotoxicity. Endocrine Practice, 8, 222-224. https://doi.org/10.4158/EP.8.3.222

[12] Karalus, M., Jade Tamatea, A.U., Conaglen, J.V. and Elston, M.S. (2016) Carbimazole-Induced Hepatotoxicity-Avoid Rechallenging. JSM Thyroid Disorders \& Management, 1, 1001.

[13] Burgin, S., Zanetto, U., Cooney, R. and Basu, A. (2015) A Rare Case of Carbimazole-Induced Hepatitis in a Patient with Graves' Disease. Journal of the Royal Society of Medicine Open, 6, 1-2. https://doi.org/10.1177/2054270415602827

[14] Marazuela, M., Sánchez de Paco, G., Jiménez, I., Carraro, R., Fernández, H.J. and Pajares, J.M. (2002) Acute Pancreatitis, Hepatic Cholestasis, and Erythema Nodosum Induced by Carbimazole. Endocrine Journal, 49, 315-318. https://doi.org/10.1507/endocrj.49.315

[15] Williams, K., et al. (1997) Fifty Years of Experience with Propylthiouracil Associated Hepato-Toxicity: What Have We Learned? JCEM, 82, 1727-1733. 